\title{
CHALLENGES IN CONTEMPORARY HEALTH TECHNOLOGY ASSESSMENT: A VIEW FROM THE OUTSIDE-ERRATUM
}

Wija Oortwijn, Gert Jan van der Wilt

doi.org/10.1017/S0266462316000143. Published online by Cambridge University Press, 11 April 2016

Owing to a copyediting error, Marjukka Mäkelä was incorrectly listed as an author in the editorial by Oortwijn \& van der Wilt (1) in February/April 2016 issue of International Journal of Technology Assessment in Health Care. The publisher apologizes to the author and readers for this error. The original article has been corrected online to rectify this error.

\section{REFERENCE}

1. Oorwijn W \& van der Wilt GJ. Challenges in contemporary heath technology assessment: A view from the outside. Int J Technol Assess Health Care 2016;32:1/2. doi.org/10.1017/S0266462316000143. 